ORIGINAL ARTICLE

\title{
Biomonitoring of traffic police officers exposed to airborne platinum
}

\author{
I lavicoli, B Bocca, F Petrucci, O Senofonte, G Carelli, A Alimonti, S Caroli
}

Occup Environ Med 2004;61:636-639. doi: 10.1136/oem.2003.010744

See end of article for authors' affiliations

....................

Correspondence to: Dr I lavicoli, Institute of Occupational Health Catholic University of Sacred Heart, Largo Francesco Vito 1, 00168 Rome, Italy; iavicoli.ivo@ rm.unicatt.it

Accepted 29 January 2004

\begin{abstract}
Background: Over the past two decades there has been a substantial increase in environmental levels of palladium, platinum, and rhodium, the platinum group elements (PGEs), due to the widespread use of catalytic converters for automotive traction.

Aim: To evaluate urinary platinum levels in occupationally exposed subjects.

Methods: A total of 161 employees from the Rome City Police Force were studied; 103 were traffic police involved in controlling streets with an average flow of vehicles, while the remaining 58 were control subjects engaged only in office work. Platinum quantification in the urine samples of these subjects was carried out by sector field inductively coupled plasma mass spectrometry.

Results: There were no statistically significant differences between platinum levels in the group of subjects engaged in traffic control and the control group $(4.45(2.42) \mathrm{ng} / \mathrm{l} \vee 4.56(2.84) \mathrm{ng} / \mathrm{l}$, respectively).

Conclusions: Urinary levels were found to be higher than those reported for other urban populations, thus showing a progressive increase in human exposure to Pt.
\end{abstract}

$T$ he wide-scale use of catalytic converters for automotive traction in most industrialised countries has led, over the years, to a substantial increase in environmental concentrations of palladium, platinum, and rhodium, also known as the platinum group elements (PGEs). ${ }^{1-4}$ This new environmental threat ${ }^{5-7}$ has prompted a number of studies aimed at clarifying the PGEs' release mechanism in catalytic converters which subsequently results in atmospheric pollution. $^{89}$ The detection of PGEs, even in remote areas of the planet, provides evidence of the global nature of the problem. $^{7}$ The vast majority of studies on airborne PGEs have however been carried out in urban areas characterised by high traffic density or in areas adjoining the aforementioned zones. ${ }^{10-15}$ Medium and long term investigations have provided conclusive evidence of a constant increase in airborne quantities of PGEs, particularly Pt and Rh. ${ }^{15}$

At the low levels detected so far, the possible adverse effects of these elements on ecosystems and human health are still largely unknown. In order to shed further light on this complex issue, particularly in relation to the impact on human health, a fit-for-purpose marker of internal dose must be selected and used to quantify actual exposure, especially in individuals who perform mainly outdoor activities.

Few data are available on the human toxicokinetics of PGEs, although several methods have been developed to quantify extremely low levels of these metals in body fluids so that their intake via the inhalation route may be monitored. ${ }^{16-23}$ To date, no such studies have been undertaken on traffic police officers in a large city. Of all workers directly exposed to airborne pollutants, the traffic police officers in a city characterised by heavy traffic are probably the occupational category most at risk on account of inhalation of exhaust fumes from motor vehicles. This situation exists in some European states such as Italy following the adoption of European Directive 98/70/EEC of 13 October 1998 that made the use of catalytic converters for automotive traction compulsory. ${ }^{24}$ This provision established deadlines and ecological criteria with regard to marketed fuels for both diesel fuel and gasoline. Even prior to the adoption of the aforementioned Directive, a significant number of cars fitted with catalytic converters were present in Italy. In this context, it is worth remembering that the EEC Directive phased out the sale of leaded gasoline in the Member States starting from 1 January 2000. Nevertheless, a few Member States, including Italy, were allowed to market leaded gasoline until 1 January 2002 on account of social and economic difficulties that could have resulted from earlier implementation of the Directive.

The aim of this study was to determine urinary $\mathrm{Pt}$ concentrations in a group of 103 Rome traffic police occupationally engaged in controlling streets with an average flow of motor vehicles in order to assess exposure to airborne Pt. A further 58 subjects were selected as controls since their activities were performed primarily indoors.

\section{METHODS \\ Subjects}

The study group consisted of 161 healthy employees from the Rome City Police Force ( 84 males, mean age 44.7 (10.6) years, age range 22-62 years; 77 females, mean age 37.8 (6.7) years, age range $23-58$ years). Of these, 103 traffic police officers ( 57 males, mean age 42.6 (11.1) years, age range 2362 years; 46 females, mean age 36.4 (7.2) years, range 23-58 years) were employed in traffic control on streets with an average flow of vehicles, and 58 were chosen as control subjects (27 males, mean age 49.0 (7.9) years, age range 2260 years; 31 females, mean age 39.7 (5.6) years; range 29-54 years). The control group consisted of police officers who had been engaged in indoor activities for at least two years.

When forming the two groups of subjects, work locations were taken into consideration to ensure that different urban sites in Rome with average traffic density were represented. These sites were located particularly in central Rome, in residential areas where traffic was characterised by a "stopand-go" pattern due to the presence of zebra crossings and traffic lights. The speed limit on all city roads was $50 \mathrm{~km} / \mathrm{h}$ and traffic density was about $30000-40000$ vehicles per day. Moreover, the streets were narrow and flanked by tall buildings.

Figure 1 shows the location of the four police stations to which the police officers involved in this study belonged. All eligible subjects were interviewed and filled in a 


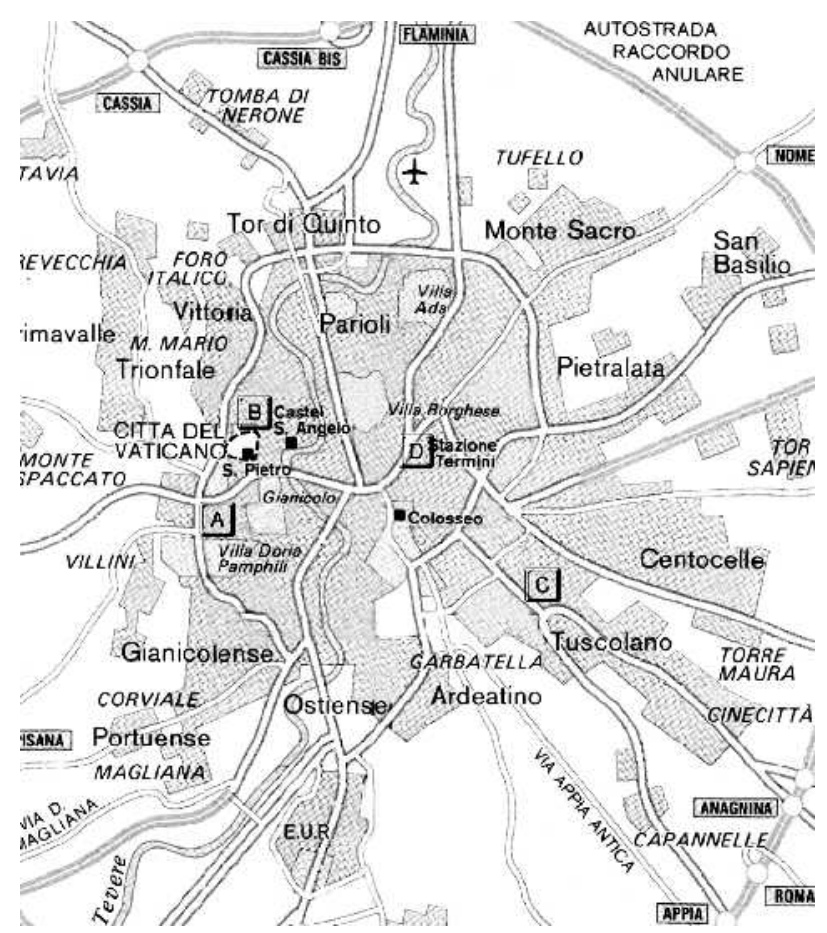

Figure 1 Map of Rome with indication of the streets where the four selected police stations were located. Traffic police officers performed their outdoor activity in the nearby streets. Police stations: (A) Via Pagano; (B) Via Crescenzio; (C) Via Macedonia; (D) Via Goito.

questionnaire. Personal data included gender, age, weight, height, presence of noble metal medical devices, general state of health, use of pharmaceuticals, dietary habits, alcohol consumption, coffee consumption, physical exercise, residence type (urban or extra-urban), and duration of employment.

The planned study was performed during July-August 2001 and was approved by the Ethics Committee of the Catholic University of the Sacred Heart of Rome and by the Istituto Superiore di Sanità (Italian National Institute of Health). All subjects gave their informed consent after the objectives of the investigation had been illustrated.

\section{Sample collection and treatment}

Urine samples were collected at the beginning and at the end of the seven hour outdoor and indoor work shifts. To this end, $50 \mathrm{ml}$ polyethylene vials (Kartell, Milan, Italy) were used. The tubes were first decontaminated overnight with $10 \% \mathrm{HNO}_{3}$, then rinsed several times with high purity deionised water (Idrolab-a System, Idron, Rome, Italy). Samples were frozen within two hours of collection and stored at $-20^{\circ} \mathrm{C}$ until analysis. To preserve the integrity of the urine samples and to minimise contamination or phenomena of loss of the analytes, all subsequent treatments of the specimens were performed in a class-100 clean room (Tamco, Rome, Italy). After thawing at room temperature and shaking, $1 \mathrm{ml}$ aliquots were sub-sampled from the original urine samples and simply diluted $\mathrm{l}+4(\mathrm{v} / \mathrm{v})$ with high purity water.

\section{Analysis}

Standard working solutions were prepared daily in polyethylene tubes (Falcon, Necton Dickinson, Lincoln Park, NJ, USA) by dilution of the stock solution of $1000 \mathrm{mg} / \mathrm{l} \mathrm{Pt}$ (Spex, Edison, NJ, USA). Calibration was performed in the standard addition mode so as to keep the matrix induced variations under control. A pooled urine sample diluted $1+4(\mathrm{v} / \mathrm{v})$ with high purity water was measured frequently during the analytical sequence in order to compensate for possible instrumental drifts. This control sample was also used for the evaluation of the intra- (ten replicate measurements) and inter-day (repeated on five different analytical cycles) repeatability. Due to the lack of appropriate certified reference material containing $\mathrm{Pt}$ at the level of interest, recovery tests were performed by adding $2 \mathrm{ng} / \mathrm{l} \mathrm{Pt}$ to pooled urine in order to check the recovery of the method and thus estimate its accuracy. Urine density measurements were performed using a densimeter, model DMA 35N (PBI International, Milan, Italy).

Platinum quantification was achieved by sector field inductively coupled plasma mass spectrometry (SF-ICP-MS) using an element spectrometer (ThermoFinnigan, Bremen, Germany) coupled to a pneumatic nebuliser. Determinations were carried out at mass 195 in the low resolution mode $(\Delta \mathrm{m} / \mathrm{m}=300)$. The major interferent on mass $195 \mathrm{amu}$ of $\mathrm{Pt}$ in the urine matrix was the double ion ${ }^{179} \mathrm{Hf}^{16} \mathrm{O}$, but given the low concentration of $\mathrm{Hf}$ in urine, the influence of $\mathrm{HfO}^{+}$ was found to be of no practical consequence. Equipment and settings of the SF-ICP-MS approach have been described in detail elsewhere. ${ }^{22}$

\section{Statistical evaluation}

The statistical package SPSS (SPSS Inc., Chicago, IL, USA) was used for the processing of experimental data. Mean, standard deviation (SD), and centiles were calculated after normalisation to urinary density to control possible variations during the day. Pt distribution was tested for normality by the Kolmorogov-Smirnov test (K-S). The association between indoor and outdoor Pt exposure (that is, police officers control group versus police officers group exposed to traffic) as well as the difference in urinary levels at the beginning and end of the shift were evaluated by means of analysis of variance (ANOVA). Gender and age (four groups: $\leqslant 30,31-$ $40,41-50, \geqslant 51$ years) were also tentatively considered as major variables. For the ANOVA test, $p$ values $<0.05$ were considered to be significant.

\section{RESULTS}

The relevant analytical features of the SF-ICP-MS determinations were as follows: recovery, 99.0 (2.6)\%; limit of detection (LoD), calculated as $3 \sigma$ of 10 blank determinations, $0.2 \mathrm{ng} / \mathrm{l}$; repeatability intra- and inter-day, $1.9 \%$ and $5.0 \%$, respectively.

Since the K-S test revealed normal Pt distribution in the urine of control and exposed subjects, analytical values were used without further treatment.

Table 1 illustrates the basic statistical data processing for urinary Pt in control and exposed subjects. The third and fourth columns of this table report data grouped according to the time of urine collection (beginning or end of shift), while the last two columns show cumulative concentrations as a function of gender. Data for 12 individuals had to be excluded from statistical analysis because of the presence of noble metal dental restorations that could have contributed to urinary Pt levels. ${ }^{25} 26$

No other noble metal medical devices were present in any of the subjects. Data below LoDs in six subjects (two controls and four exposed police officers) were also excluded from calculation of means. Thus, the so-called "useful values" relating to 49 control subjects and 94 exposed police officers, were obtained from the a priori exclusion criterion as well as from the a posteriori analytical exclusion.

No significant differences were found in the urine levels of the two groups of subjects at the beginning and end of the work shift: mean values of $4.52 \mathrm{ng} / \mathrm{l}$ at the beginning $v$ $4.64 \mathrm{ng} / \mathrm{l}$ at the end in control subjects $(\mathrm{p}=0.35)$, and $4.43 \mathrm{ng} / \mathrm{l} \quad v \quad 4.63 \mathrm{ng} / \mathrm{l}$ in exposed subjects $(\mathrm{p}=0.45)$. 


\begin{tabular}{|c|c|c|c|c|c|}
\hline & BoS and EoS* & BoS & EoS & $\begin{array}{l}\text { Females } \\
\text { (BoS and EoS*) }\end{array}$ & $\begin{array}{l}\text { Males } \\
\text { (BoS and EoS*) }\end{array}$ \\
\hline \multicolumn{6}{|c|}{ Control subjects $†$} \\
\hline Mean & 4.56 & 4.52 & 4.64 & $\begin{array}{l}4.09 \\
273\end{array}$ & 5.77 \\
\hline SD & 2.84 & 2.37 & 3.28 & 2.73 & 3.68 \\
\hline $5-95 \%$ range & $0.55-10.10$ & $0.87-9.60$ & $0.53-10.79$ & $0.40-10.18$ & $0.64-15.16$ \\
\hline \multicolumn{6}{|c|}{ Exposed subjects $\ddagger$} \\
\hline Mean & 4.45 & 4.43 & 4.63 & 4.63 & 5.04 \\
\hline SD & 2.42 & 2.34 & 2.47 & 2.28 & 3.38 \\
\hline $5-95 \%$ range & $0.81-8.91$ & $1.09-9.05$ & $0.91-9.64$ & $1.09-9.49$ & $0.74-11.75$ \\
\hline $\begin{array}{l}\text { BoS, beginning of } \\
\text { *Data refer to coll } \\
\text { †Police engaged i } \\
\ddagger \text { Police engaged }\end{array}$ & $\begin{array}{l}\text { shiff; EoS, end c } \\
\text { ections at the bes } \\
\text { in office work (m) } \\
\text { in traffic control ( }\end{array}$ & $\begin{array}{l}\text { hiff. } \\
\text { ning and the } \\
\text { mum numbe }\end{array}$ & $\begin{array}{l}\text { end of shiff. } \\
\text { of "useful val }\end{array}$ & $\begin{array}{l} \\
\text { ": :49). } \\
\left(\operatorname{es}^{\prime \prime}: \text { 94). }\right.\end{array}$ & \\
\hline
\end{tabular}

Furthermore, no significant differences were observed when the control and exposed individuals were compared-either at the beginning or at the end of the work shift (mean values of $4.52 \mathrm{ng} / \mathrm{l} v 4.43 \mathrm{ng} / \mathrm{l}$ at the beginning with $\mathrm{p}=0.66$, and $4.64 \mathrm{ng} / \mathrm{l} v 4.63 \mathrm{ng} / \mathrm{l}$ at the end with $\mathrm{p}=0.60$ ). The same pattern was obtained by comparing the data clustered only by exposure without distinguishing between the beginning and the end of the workday (control $v$ exposed individuals, $\mathrm{p}=0.90)$, and the experimental range was $0.20-15.29 \mathrm{ng} / \mathrm{l}$ (median $4.34 \mathrm{ng} / \mathrm{l}$ ) in control subjects, and $0.28-13.67 \mathrm{ng} / \mathrm{l}$ (median $4.51 \mathrm{ng} / \mathrm{l}$ ) in exposed subjects. Table 2 shows $\mathrm{Pt}$ concentration as a function of age for both groups of workers.

\section{DISCUSSION AND CONCLUSIONS}

It is interesting to note that the data obtained in this study reveal no significant differences between exposed and control police officers in terms of urinary Pt excretion (table 1). This would suggest that the release of airborne Pt has an equal effect on the indoor and outdoor environment. Urinary Pt concentrations in the two groups of subjects tested in this study are possibly due to similar sets of exposure conditions since all subjects lived in the same region, and it could therefore be inferred that their global exposure to Pt through environment and diet was rather similar. Unfortunately, no data are available concerning the intake of Pt with food in Italy. In 1994, for the UK population, total Pt intake with diet was reported to be $0.02 \mu \mathrm{g} /$ day. ${ }^{27}$ In the present study, with the exception of one vegetarian subject belonging to the exposed group, all individuals claimed to be on a mixed diet.

The absence of statistically significant variations in the urinary Pt concentrations observed at the beginning and at the end of the work shift may be explained by assuming that

Table 2 Urinary Pt concentration in police officers grouped by age

\begin{tabular}{lcl}
\hline Age (years) & Subjects (no.) & Mean (SD)* ${ }^{*}$ (ng/l) \\
\hline Control subjectst & & $1.62(1.29)$ \\
$\leqslant 30$ & 2 & $3.98(3.18)$ \\
$31-40$ & 19 & $6.35(3.38)$ \\
$41-50$ & 18 & $4.30(2.30)$ \\
$\geqslant 51$ & 10 & \\
Exposed subjects $\ddagger$ & & $4.51(2.30)$ \\
$\leqslant 30$ & 19 & $4.30(2.55)$ \\
$31-40$ & 34 & $5.16(2.87)$ \\
$41-50$ & 20 & $5.75(3.81)$ \\
$\geqslant 51$ & 21 &
\end{tabular}

*Data referred to collections at the beginning and end of shift. †Police officers engaged in office work (number of "useful values": 49). $\ddagger$ Police officers engaged in traffic control (number of "useful values": 94). the Pt half life at the exposure levels detected in this study is far longer than the duration of the work shift.

Furthermore, the statistical parameters reported in table 1 show significant differences when gender was considered as a discriminative variable in control groups $(p=0.004)$, since mean concentration for males was higher than for females ( $5.77 \mathrm{ng} / \mathrm{l} v 4.09 \mathrm{ng} / \mathrm{l}$ ). Although this is an interesting result, it has no confirmation in the literature. In fact, in a recent study, Herr and colleagues ${ }^{25}$ failed to find significant differences between male and female subjects. It would therefore be useful to carry out studies on wider populations. No significant statistical differences between control and exposed subjects were observed within each gender group $(\mathrm{p}=0.28$ and $\mathrm{p}=0.25$ in the female and male groups, respectively).

With regard to the age group variable (table 2), it is apparent that Pt levels in exposed police officers were higher than those found in control subjects aged $\leqslant 30$ years and in the range 31-40 years. Moreover, both exposed and control subjects aged $\geqslant 41$ years showed statistically significant higher mean $\mathrm{Pt}$ concentrations than those of younger colleagues $(\mathrm{p}=0.03$ and $\mathrm{p}=0.02$ for controls $v$ controls and exposed $v$ exposed, respectively). On the other hand, no statistical significance was found between the occupationally exposed group and controls in subjects over 41 years $(p=0.4)$. In general, age is associated with an increase in urinary Pt, as if this metal accumulated in the body over the years as a consequence of multiple sources of exposure (Spearman's $\rho=0.147, \mathrm{p}=0.01$ ).

The lack of data in this field enables us to make only a few general comments. One of the first investigations on urinary Pt levels in the Italian population was undertaken by Minoia and colleagues. ${ }^{28}$. Twenty five subjects were tested and results were always below $1 \mu \mathrm{g} / \mathrm{l}$. This was due to the fact that the technique employed had a detection ability inferior to that of SF-ICP-MS. Much higher values than those found in the present study were reported by Vaughan and Florence. ${ }^{29}$ For urinary Pt concentration, these authors found an average of $0.25 \mu \mathrm{g} / \mathrm{l}, 0.18 \mu \mathrm{g} / \mathrm{l}$ (median), and 0.02-0.92 $\mu \mathrm{g} / \mathrm{l}$ (range) for a group of 21 subjects living in Sydney. A wider study on 496 subjects from various areas of the USA gave a mean value for Pt of $1.52 \mu \mathrm{g} / \mathrm{l}$, with a 95th centile of $4.22 \mu \mathrm{g} / \mathrm{l}^{30}$ The improvement of LoDs due to the development of novel analytical techniques has recently enabled detection of urinary $\mathrm{Pt}$ concentrations in the $\mathrm{ng} / \mathrm{l}$ range-that is, an improvement of three orders of magnitude compared to a few years ago.

In our study, the urinary $\mathrm{Pt}$ concentration range in occupationally exposed police officers $(0.28-13.67 \mathrm{ng} / \mathrm{l})$ was comparable not only to that of the control group (0.20$15.29 \mathrm{ng} / \mathrm{l})$, but also to that observed in children in the same 
city $(<0.6-9.5 \mathrm{ng} / \mathrm{l}),{ }^{22}$ while it was found to shift to higher concentrations in comparison with the range reported by Begerow and Dunemann for the urine of an urban population (0.3-2.2 ng/l) and of road workers (0.1-4.4 ng/l) ${ }^{31}$ In recent studies conducted by Herr et al and Becker and colleagues, 2526 wider ranges of Pt urinary concentrations were reported in the general population $(<0.9-65.5 \mathrm{ng} / \mathrm{l}$ and $<0.1-185 \mathrm{ng} / \mathrm{l}$, respectively). The Pt median value $(4.51 \mathrm{ng} / \mathrm{l})$ found for exposed police officers was higher than the median value given by Schierl, for Pt in population groups exposed to traffic, such as bus drivers $(2.8 \mathrm{ng} / \mathrm{l})$ and taxi drivers $(1.3 \mathrm{ng} / \mathrm{l}){ }^{23}$

The outcome of this study provides further evidence of the need for systematic biomonitoring of urban populations for PGEs pollution. Although environmental levels of PGEs are still relatively low, recent reports of a progressive increase in these concentrations makes further research essential.

\section{Authors' affiliations}

I lavicoli, G Carelli, Institute of Occupational Health, Catholic University of Sacred Heart, Largo Francesco Vito 1, 00168 Rome, Italy

B Bocca, F Petrucci, O Senofonte, A Alimonti, S Caroli, Istituto Superiore di Sanità, Viale Regina Elena 299, 00161 Rome, Italy

\section{REFERENCES}

1 Gómez B, Palacios MA, Gómez M, et al. Levels and risk assessment for humans and ecosystems of platinum-group elements in the airborne particles and road dust of some European cities. Sci Total Environ 2002;299:1-19.

2 Jarvis KE, Parry SJ, Piper JM. Temporal and spatial studies of autocatalystderived platinum, rhodium, and palladium and selected vehicle-derived trace elements in the environment. Environ Sci Technol 2001;35:1031-6.

3 Ely JC, Neal CR, Kulpa CF, et al. Implications of platinum-group element accumulation along U.S. roads from catalytic-converter attrition. Environ Sci Technol 2001;35:3816-22.

4 Bocca B, Petrucci F, Alimonti A, et al. Traffic-related platinum and rhodium concentration in the atmosphere of Rome. J Environ Monit 2003;5:563-8.

5 Moldovan M, Rauch S, Gómez M, et al. Bioaccumulation of palladium, platinum and rhodium from urban particulates and sediments by the freshwater isopod Asellus aquaticus. Wat Res 2001;35:4175-83.

6 Jensen KH, Rauch S, Morrison GM, et al. Platinum group elements in the feathers of raptors and their prey. Arch Environ Contam Toxicol 2002;42:338-47.

7 Barbante C, Veysseyere A, Ferrari C, et al. Greenland snow evidence of large scale atmospheric contamination for platinum, palladium and rhodium. Environ Sci Technol 2001;35:835-9.

8 Moldovan M, Palacios MA, Gómez MM, et al. Platinum-elements: quantification in collected exhaust fumes and studies of catalyst surfaces. Sci Total Environ 2000;257:1-15.

9 Moldovan M, Palacios MA, Gómez MM et al. Environmental risk of particulate and soluble group elements released from gasoline and diesel engine catalytic converters. Sci Total Environ 2002;296:199-208.

10 Schierl R. Urinary biomonitoring of platinum in occupational medicine. In: Zereini F, Alt F, eds. Anthropogenic platinum-group element emissions. Their impact on man and environment. Springer-Verlag: Berlin, 1999:173-80.
11 Tilch J, Schuster M, Schwarzer M. Determination of palladium in airborne particulate matter in a German city. Fresenius J Anal Chem 2000;367:450-3.

12 Gómez B, Gómez N, Sanchez JL, et al. Platinum and rhodium distribution in airborne particulate matter and dust roads. Sci Total Environ 2001;269:131-44

13 Probst TU, Rietz B, Aflassi ZB. Platinum concentration in Danish air samples determined by instrumental neutron activation analysis. J Environ Monit 2001;3:217-19.

14 Rauch S, Lu M, Morrison GM. Heterogeneity of platinum group metals in airborne particles. Environ Sci Technol 2001;1:595-9.

15 Zereini F, Wiseman C, Alt F, et al. Platinum and rhodium concentrations in airborne particulate matter in Germany from 1988 to 1998. Environ Sci Technol 2001;35:1996-2000.

16 Messerschmidt J, Alt F, Told G, et al. Adsorptive voltammetric procedure for the determination of platinum baseline levels in humans body fluids. Fresenius J Anal Chem 1992;343:391-4.

17 Begerow J, Turfeld M. Dunemann L. Determination of physiological platinum levels in human urine using magnetic sector field inductively coupled plasma mass spectrometry in combination with ultraviolet photolysis. J Anal At Spectrom 1996;11:913-16.

18 Begerow J, Turfeld M. Dunemann L. Determination of physiological palladium and platinum levels in urine using double focusing magnetic sector field ICPMS. Fresenius J Anal Chem 1997;359:427-9.

19 Schramel P, Wendler I, Angerer J. The determination of metals (antimony, bismuth, lead, cadmium, mercury, palladium, platinum, tellurium, thallium, tin and tungsten) in urine samples by inductively coupled plasma-mass spectrometry. Int Arch Occup Environ Health 1997;69:219-23.

20 Krachler M, Alimonti A, Petrucci F, et al. Analytical problems in the determination of platinum-group metals in urine by quadrupole and magnetic sector field inductively coupled plasma mass spectrometry. Anal Chim Acta 1998;363:1-10.

21 Begerow J, Turfeld M, Dunemann L. New horizons in human biomonitoring of environmentally and occupationally relevant metals-sector field ICP-MS versus electrothermal AAS. J Anal At Spectrom 2000;15:347-52.

22 Caroli S, Alimonti A, Petrucci F, et al. Assessment of exposure to platinumgroup metals of urban children. Spectrochimica Acta B 2001;56:1241-8.

23 Schierl R. Environmental monitoring of platinum in air and urine. Microchem J 2000;67:245-8.

24 Direttiva 98/70/CE del Parlamento Europeo e del Consiglio del 13 ottobre 1998 relativa alla qualità della benzina e del combustibile diesel e recante modificazione della direttiva 93/12/CEE del Consiglio.

25 Herr CE, Jankofsky M, Angerer J, et al. Influences on human internal exposure to environmental platinum. J Expo Anal Environ Epidemiol 2003;13:24-30.

26 Becker K, Schulz C, Seiwert M, et al. German environmental survey 1998 (GerES III): environmental pollutants in the urine of the German population. Int J Hyg Environ Health 2003;206:15-24.

27 Ysart G, Miller P, Crews $H$, et al. Dietary exposure estimates of 30 elements from the UK Total Diet Study. Food Additives and Contaminants 1999; 16:391-403.

28 Minoia C, Sabbioni E, Apostoli $P$, et al. Trace element reference values in tissues from inhabitants of the European Community I. Study of 46 elements in urine, blood and serum of Italian subjects. Sci Total Environ 1990;95:89-105.

29 Vaughan GT, Florence TM. Platinum in the human diet, blood, hair and excreta. Sci Total Environ 1992;111:47-58.

30 Paschal DC, Ting BG, Morrow JC et al. Trace metals in urine of United States residents: reference range concentrations. Environ Res Section A 1998;76:53-9.

31 Begerow J, Dunemann L. Internal platinum and palladium exposure of the general population with emphasis on the exposure from automobile exhaus and dental restorative alloys. In: Zereini F, Alt F, eds. Anthropogenic platinumgroup element emissions. Their impact on man and environment. SpringerVerlag: Berlin, 1999:227-36. 